\title{
A panoramic view of the LATVI - Virtual and Intelligent Technologies Laboratory
}

\author{
Rosa Maria E. Moreira da Costa, Vera Maria B. Werneck, Alexandre Sztajnberg \\ DICC - Departamento de Informática e Ciência da Computação \\ IME - Instituto de Matemática e Estatística \\ UERJ - Universidade do Estado do Rio de Janeiro \\ Rio de Janeiro- RJ - Brazil \\ \{rcosta,vera,alexszt\}@ime.uerj.br
}

\begin{abstract}
In this paper we present an overview of the LATVI Laboratório de Tecnologias Virtuais e Inteligentes (Laboratory of Virtual and Intelligent Technologies) at the Rio de Janeiro State University. The mission and main objectives are discussed. Current and ongoing projects are outlined.
\end{abstract}

Keywords - 3D models; virtual reality; application integration

\section{INTRODUCTION}

The LATVI- Laboratory of Virtual and Intelligent Technologies was created to support research activities focusing on the Mathematics-Statistics-Computer Science and experimentations of Software Engineering, Complex Systems, Distributed Parallel and Distributed Computing, Neuroscience, Virtual Reality, Ubiquitous Applications, among others. Researchers participate in inter-institutional projects and interdisciplinary cooperation with physicians, nutritionists, biologists, physicists, and professionals from various fields of Engineering.

In this context, this paper describes the purposes of LATVI, its research areas and the most important development projects.

This paper is organized as follows. Section 2 gives the mission of the LATVI. Section 3 lists the lab objectives, stressing some of our research group's previous works. Section 4 describes the ongoing projects. Section 5 concludes the paper and presents future work.

\section{LAB HISTORY AND MISSION}

The history of LATVI is very recent. It was created to support the reformulation of the Computer Science curriculum of the BS program and the creation of a Computer Science master's degree program. These changes and the new graduation course encouraged research activities in different fields of Computer Science in the areas of expertise of the staff.

In this context, LATVI has the mission to support research and development activities; to improve activities of human resources training; and to transfer research knowledge to the society and to the health sector.

\section{LAB OBJECTIVES}

Nowadays, health and technology areas are investigating new applications that extend the possibilities of training and treatment of various disorders and diseases, exploring new information and communication technologies. Recently, some results have opened new possibilities to the health care area [1], [2], [3]. In general, they integrate Virtual Reality, Mobile and Artificial Intelligence techniques to increase the humancomputer interaction.

In this sense, LATVI aims at supporting the development of studies that are based on scientific computing and applications in medicine, especially computer modeling and simulation of physiological systems, promoting the development of medical imaging, scientific visualization and virtual reality applications, computer-aided diagnosis, surgical planning and medical training.

These projects employ the most modern techniques for communication and multimedia transmission, development and management of high-performance computing environments; explore artificial intelligence techniques applied to all these processes, targeting the training of human resources and promoting technology transfer and innovation to the health assistance area.

\section{RESEARCH LinES AND ONGOING PROJECTS}

Currently, the research lines that LATVI supports are primarily related to the development of ubiquitous computing applications, Virtual Reality technology and investigate the use of Multi-Agent Systems (MAS) modeling and implementation techniques.

\section{A. Virtual Reality in Cognitive Rehabilitation}

Technology advances have been promoting changes in the activities associated with treatment, training or professional updating in the health care area. Such applications require new approaches in order to study, design, implement, and use computer systems in an effective way.

Virtual Reality encompasses advanced technologies for building human-computer interfaces, immersing the user in environments that can be actively interacted with and explored. 
In general, the user is able to navigate and interact with a threedimensional synthetic environment generated by computer programs. Exploring the human multi-sensory channels, diverse types of stimuli can be transmitted by specific devices and perceived by one or more user's senses [4].

Recently, Virtual Reality (VR) technology has been widely used in the Cognitive Rehabilitation (CR) area, obtaining positive results [5], [6], [7]. The introduction of VR in the CR area is considered as a new opportunity to diminish the difficulties involved in the CR process, making the associated activities more motivational and fun.

In many applications there is a strong dependence on the therapist's intervention to control the patient's navigation, to change the level of difficulty of a task, to go back to an earlier stage, or to control the sequence of activities in a synthetic environment. The LATVI research group has developed some experiments to integrate intelligent strategies in the VR environments in order to control the users' navigation, changing the level of difficulty of a task and proposing tasks in an automated way. The inclusion of intelligent agents in the virtual environments could reduce the need of therapists' involvement in the activity that can improve treatment. The therapists can just assist the activity without interaction.

An agent can be considered an autonomous system seeking different ways to reach pre-established goals in a real or virtual environment [8]. Every agent must have autonomy, which means that an agent must have the ability to manage its internal state and its actions to achieve their goals without human intervention. A multi-agent system is composed of two or more agents who have a set of skills and plans in order to achieve their goals. In order to develop these environments some serious games were developed aiming at improving the cognitive functions in patients with neuropsychiatric disorders [1]. The games were developed using agents, 3D and Virtual Reality technologies. They control the right and wrong answers, changing the difficulty level of the tasks according to the user performance. Figure 1 shows an example of the game scene.

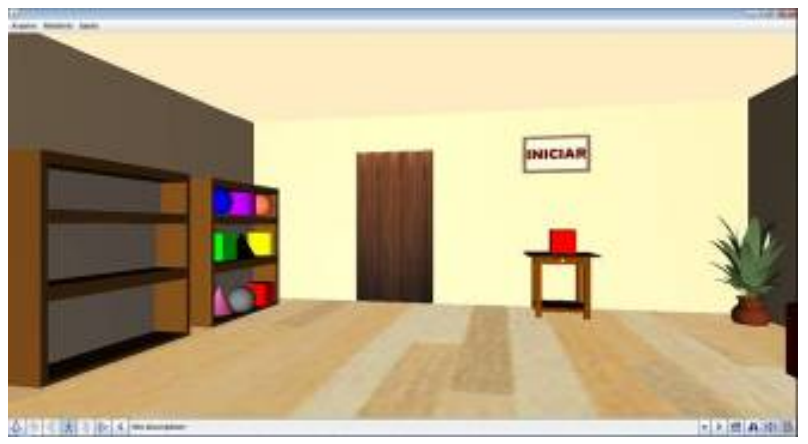

Figure 1. Example of the Smeck-3D scene for stimulating cognitive functions
B. Virtual reality supporting developer-client communication and training

Our lab actively collaborates with other research groups. The main action line is to help these groups to use 3D and VR tools for training and to facilitate communication between the developer, which usually employs specific domain languages, and the client or user. In many cases 3D interfaces and VR immersion can provide a better vision of the project.

Currently our lab is working in two such projects: (i) a remote assisted living application and (ii) a 3D-VR tool, called ScketchUp_Access, which provides the architect appropriate means to design inclusive (for disabled people) environments.

In the first case, a typical setting involves sensors that collect data from the patient and send this data to a monitoring center (a clinic, a doctor, a hospital). In this approach, we incorporate local intelligence at home: ambient sensors in the house and sensors worn by the patient constantly generate data, which is collected by a local computer system that interprets them using medical knowledge. The identification of a patient's abnormal condition can activate a local device (e.g., turning on an air conditioning appliance), start an interaction with the person (e.g., through a TV screen) or send an emergency message to a monitoring center. The software infrastructure of the system broadly uses ubiquitous and context-aware techniques.

We developed a 3D simulator to help the developers of the context-aware infrastructure verify the system overall behavior (Figure 2). The developer can interact with the 3D vision pressing the on-off buttons or moving the patient's icon around the environment while checking if the Resource Agents and context information protocol are flowing as expected [9].

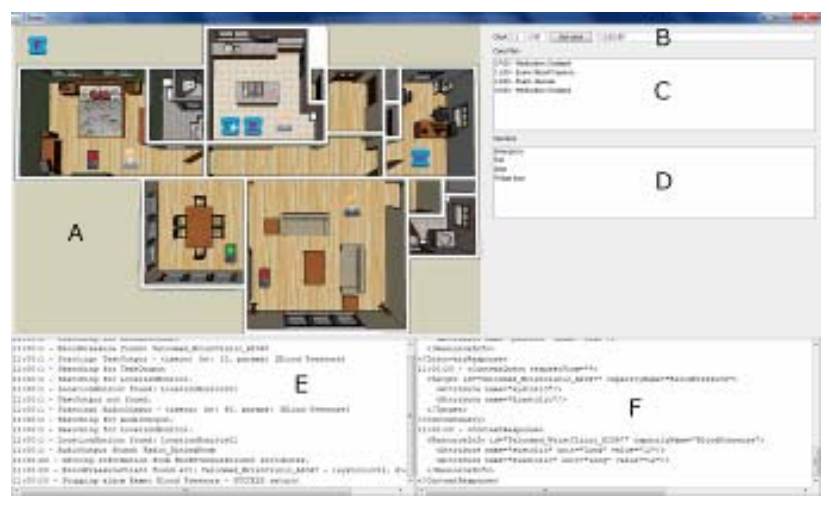

Figure 2. 3D Simulator for a remote assisted living application deployed in a smart home intelligent ambient

We are now developing a VR version in which the patient, care-givers, family and medical staff will have the opportunity to try the environment in an immersive way. The patient will have a good idea how his or her life will be affected by sensors and wearable devices. Care-givers and medical staff will use the VR ambient for training purposes, testing how the sensors or wireless medical equipment have to be used in addition to experimenting the interaction graphic interfaces, which are 
available through the Web. An adequate framework is being developed to be easily reused in different houses and disease configurations.

In the second case, we have been collaborating with civil architects that have been facing problems to include appropriate equipment for disabled people in their projects. According to NBR9050 Brazilian standard, all buildings have to comply with a set of requirements for disabled people regarding accessibility and social inclusion. This also includes old and historical preserved buildings [10].

Even being skilled while using 3D editors to build their architectural models, architects have enormous difficulty to include every NBR9050 mandatory detail. The standard is way detailed and the details are very specific.

We have built a set of tools, called SketchUp_Access, which extends the popular Google's Scketch_Up 3D editor with a 3D library and an on-line help that facilitates and induces the architect to use the correct equipment while strictly adhering to the standard. Figure 3 presents an example where the architect includes a backing bar with the correct dimensions and correct positioning for disabled people.
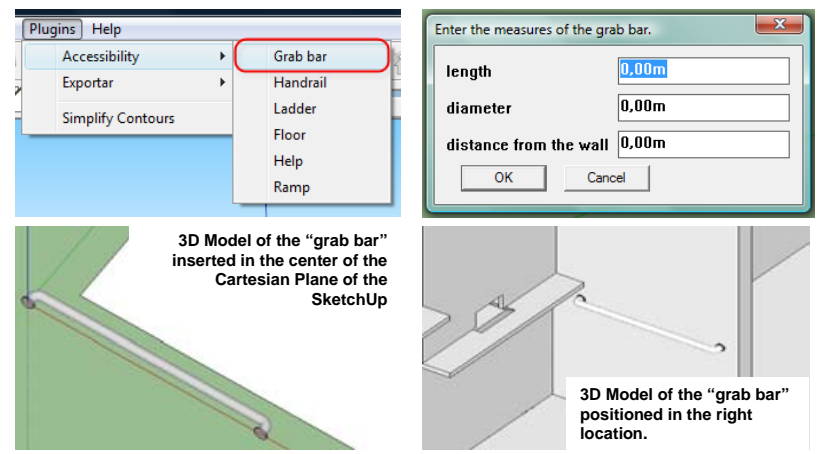

Figure 3. SketchUp_Access selecion menus and equipment insertion

After producing the 3D model, which now includes the appropriate equipment according to the standard, performing simple steps we have designed, the architect is able to transfer the 3D model to a VR environment. Figure 4 presents the same example of Figure 3 in the Blender tool used for that purpose.

With these set of tools the architect can present to the client a near-real result of how the equipment for disabled people will interfere in the ambient. A preliminary evaluation with a group of architecture professionals indicates that this approach is very useful.

\section{CONCLUDING REMARKS}

Nowadays, there is an increasing demand for using new technologies in different knowledge areas. This paper has presented the main characteristics of the LATVI Laboratory, discussing the main ongoing research activities that primarily regard to the health area.

Finally, we emphasize the need to integrate a multidisciplinary team to overcome some technical challenges that may arise from the health care area. In this sense, we stress that further research and applications in VR and MAS integration are necessary and will benefit from a welldeveloped and adequate working paradigm to integrate good health practices, technologies and individuals.
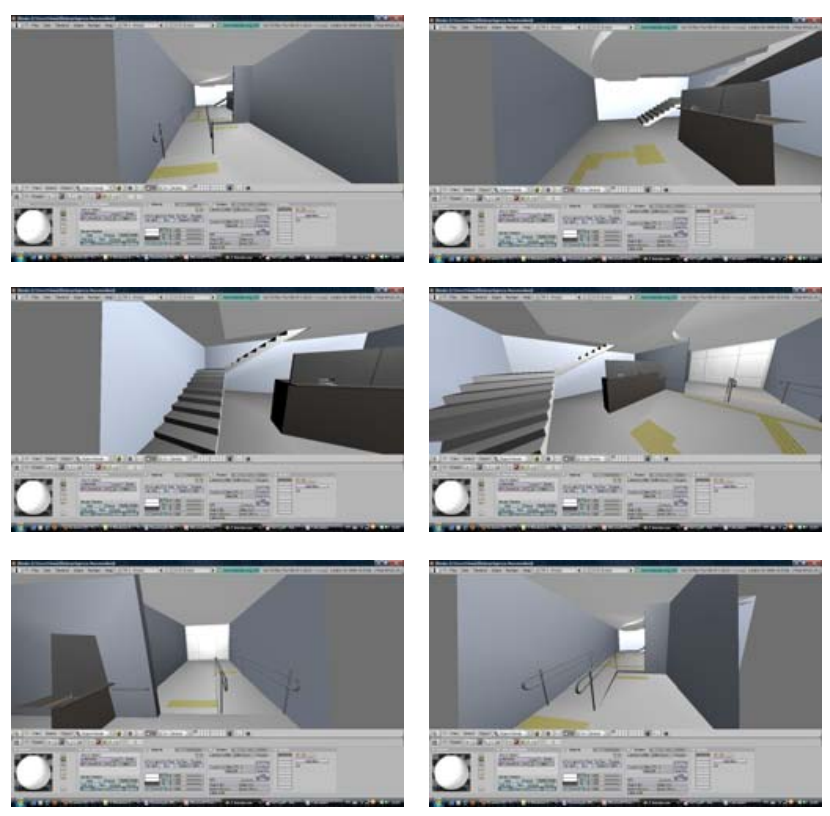

Figure 4. Virtual Environment

\section{ACKNOWLEDGMENTS}

The authors would like to acknowledge FAPERJ for the partial funding of LATVI activities and infrastructure.

This study is supported in part by the "Instituto Nacional de Ciencia e Tecnologia - Medicina Assistida por Computação Cientifica” (Medicine assisted by Scientific Computation), Brazil. Grant E-26/170.030/2008.

\section{REFERENCES}

[1] P. F. Abreu,, L. A. V. Carvalho, V. M. B. Werneck, Costa, R. M. E. M. Integrating Multi-agents in a 3D Serious Game Aimed at Cognitive Stimulation. Lecture Notes in Computer Science, v. 6774, p. 217-226, 2011.

[2] S. Carvalho, A. Copetti, O. Loques. Um Sistema Computacional Inteligente de Assistência Domiciliar à Saúde. XII Congresso Brasileiro de Informática em Saúde, CBIS 2010. Porto de Galinhas, 2010 (in Portuguese)

[3] M. Gerardi, J. Cukor, ,J. Difede, A. Rizzo, B. Rothbaum. Virtual Reality Exposure Therapy for Post-Traumatic Stress Disorder and Other Anxiety Disorders. Current Psychiatry, Vol. 12, N. 4, pp. 298-305, 2010.

[4] G. Burdea, P. Coiffet, Virtual Reality Technology. New Jersey : John Wiley \& Sons, $2^{\text {a }}$ Ed, 2003.

[5] F. Meijer, B. L.Geudeke, E.L.V.D. Broek, Navigating through Virtual Environments: Visual Realism Improves Spatial Cognition. Cyberpsychology \& Behavior, v. 12, n. 5. 2009. 
[6] E.A.Attree, M.J.Turner, N.Cowell, A Virtual Reality Test Identifies the Visuospatial Strengths of Adolescents with Dyslexia. CyberPsychology \& Behavior, v 12, n 2. 2009.

[7] N. Josman,; E. Klinger, R. Kizony, Performance within the virtual action planning supermarket (VAP-S): an executive function profile of three different populations suffering from deficits in the central nervous system. VII International Conference Disability, Virtual Reality \& Associated Technologies (ICDVRAT), Portugal: Maia. 2008.
[8] M. J. Wooldridge. An Introduction to Multi-Agent Systems. John Wiley and Sons Limited: Chichester, 2009.

[9] L. B. Negris. Uso de ontologia em serviço de contexto e descoberta de recursos para autoadaptação de sistemas. Masters Thesis, PEL/UERJ, 2011. (in Portugese)

[10] S. R. Rodrigues. Aplicando modelos 3D em realidade virtual para inclusão de requisitos de acessibilidade em projetos arquitetônicos. Masters Thesis, CComp/UERJ, 2011. (in Portugese) 